RESEA R CH NOTE

\title{
Dark refraction shift with allowance for astigmatism
}

\section{WDH Gillan* and WF Harris**}

Optometric Science Research Group, Department of Optometry, University of Johannesburg, PO Box 524, Auckland Park, 2006 South Africa

<wdhg@na.rau.ac.za>

\section{Abstract}

Purpose: To show that the dark refraction shift (dark focus) is a more complicated phenomenon than implied when presented as spherical.

Methods: Fifty autorefractor measurements of refractive state of the right eye were obtained in light and dark conditions. Multivariate methods were used to analyze the data and stereo-pair scatter plots, polar meridional profiles and other means of presenting results are used to show important characteristics of the dark refraction shift.

Results: The complexity of the dark refraction shift is indicated by stereo-pair scatter plots showing the amount of stigmatic and antistigmatic variation that occurs in light and dark conditions. The mean dark refraction shift is presented in a complete manner including all three components of refractive state. The greater variance and covariance under dark conditions is clearly shown by the term-by-term dark-light variance-covariance ratio and polar profiles of variance and covariance.

Conclusions: The dark refraction shift is a more complicated phenomenon than implied by representations as purely spherical in nature.

Keywords: dark refraction shift, dark focus, multivariate methods, stigmatic, antistigmatic, polar profiles.

The refractive state of the human eye is rarely purely stigmatic (spherical) in nature. Accommodation can induce astig- matic change in refractive state ${ }^{1}$. However, as far as we are aware, studies investigating the dark focus report findings in which the dark focus is recorded as spherical only. In many instances the technique used to measure the dark focus is limited to spherical measurements ${ }^{2-13}$, in other instances infrared optometers are used but only the nearest equivalent sphere is recorded ${ }^{14-17}$, and in other studies no mention is made of how the infra-red optometer measurements are used to produce spherical-only recordings ${ }^{18-24}$. In some studies the researchers deliberately disable the axis rotation mechanism of the optometer and use a single, usually the vertical, meridian to determine the dark focus ${ }^{25-28}$. Apart from the use of standard deviation and standard error of the mean $^{4-8,10-11,14-15,20-22}$, no other approach is used to evaluate the characteristics of the variation of multiple measurements of refractive state under dark conditions.

We prefer the term dark refraction shift to the traditional term dark focus. Formally we define the dark refraction shift to be $\triangle F$ where $\triangle F=F_{D}-F_{L}$.

$F_{D}$ and $F_{L}$ are dioptric power matrices and represent refraction in the dark and light respectively. We believe that aspects of the dark refraction shift have been missed in the past because incomplete, purely spherical measures of the dark refraction shift have been reported. They include: the extent of stigmatic and antistig-

*DipOptom MPhil DPhil(RAU) CAS(NewEnCO) FAAO FIACLE

${ }^{* *} \mathrm{BSc}($ Eng)(Witwatersrand) MS PhD(Minnesota) BOptom(RAU) BSc(Hons)(Unisa) FAAO FRSSAf

This paper results from research conducted for the degree DPhil under the guidance of Professor WF Harris at the Rand Afrikaans

University.

Received 5 January 2005; revised version accepted 26 February 2005 
matic variation, a complete measure of variance and covariance of refraction in the dark, the relationship between light and dark condition variance and covariance as well as the changes in the characteristics of variation occurring in light and dark conditions. The purpose of this note is to illustrate these phenomena.

\section{Method}

Twenty individuals acted as subjects in this study, 10 were aged between 21 and 35 years of age (pre-presbyopes) and the other 10 were aged between 40 and 65 years of age (presbyopes). The data from only one subject (aged 21) is used in this article in the interests of brevity. This subject was selected because her findings highlighted interesting aspects of the data. All subjects were treated according to the tenets of the Declaration of Helsinki and all subjects were volunteers and gave informed consent after the research protocol had been explained to them. All subjects were selected after undergoing a battery of screening tests. A Hoya AR 550 autorefractor was used to take 50 measurements of refractive state of the right eye under two conditions, the light condition where the instrument target and the room environment were fully illuminated and the dark condition where the instrument target and room illumination were largely eliminated. Each subject spent five minutes in darkness before the dark condition measurements were taken. The autorefractor was set to
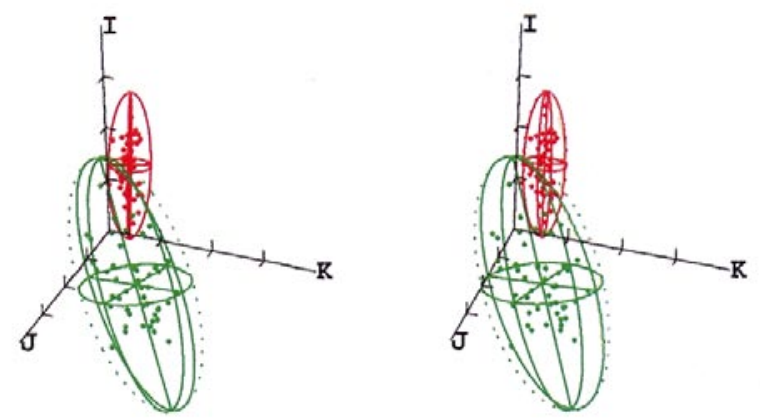

Figure 1. (a) Stereo-pair showing light (red) and dark (green) condition measurements. Included are the $95 \%$ distribution ellipsoids. The origin is $\left[\begin{array}{lll}0 & 0 & 0\end{array}\right] \mathrm{D}$ and tick intervals are $0.25 \mathbf{I}, 0.25 \mathbf{J}$ and $0.25 \mathbf{K} \mathrm{D}$. The difference in size and positioning of the two clusters show the changes in refractive state and its variation under the two stimulus conditions. measure refractive state in steps of $0.01 \mathrm{D}$ and the vertex distance was set at zero.

Power is represented as the symmetric dioptric power matrix

$$
\mathbf{F}=F_{\mathrm{st}} \mathbf{I} F_{\mathrm{or}} \mathbf{J} F_{\mathrm{ob}} \mathbf{K}
$$

where $\mathbf{I}=\left(\begin{array}{ll}1 & 0 \\ 0 & 1\end{array}\right), \mathbf{J}=\left(\begin{array}{rr}1 & 0 \\ 0 & -1\end{array}\right)$ and $\mathbf{K}=\left(\begin{array}{ll}0 & 1 \\ 1 & 0\end{array}\right)$.

$F_{\text {st }}, F_{\text {or }}$ and $F_{\mathrm{ob}}$ are the stigmatic, ortho-antistigmatic and oblique antistigmatic coefficients of the power respectively. On the face of it $F_{\mathrm{st}}, F_{\mathrm{or}}$ and $F_{\mathrm{ob}}$ are equivalent to $M, J_{0}$ and $J_{45}$ respectively defined by Thibos and coworkers ${ }^{29}$. However, the analysis here has a different basis; in contrast to their power vectors it is in terms of dioptric power matrices. Graphical representations of the matrices in symmetric dioptric power space are constructed using axes representing scalar multiples of $\mathbf{I}, \mathbf{J}$ and $\mathbf{K}$. Means are obtained as the arithmetic mean of the matrices. Variances and covariances are calculated for $F_{\mathrm{st}}, F_{\mathrm{or}}$ and $F_{\mathrm{ob}}$. All data collected were analyzed using methods developed by Harris ${ }^{30-35}$ and software developed by Malan ${ }^{36}$, Harris and Rubin ${ }^{37}$.

\section{Results}

Table 1 gives the mean refractive state (of 50 autorefractor measurements) for the light and dark condition in conventional spherocylindrical terms as well as in terms of the stigmatic $\left(F_{\mathrm{st}}\right)$ and the ortho- $\left(F_{\mathrm{or}}\right)$ and oblique $\left(F_{\mathrm{ob}}\right)$ anti-

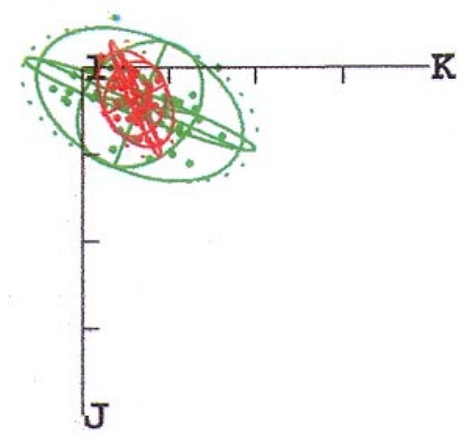

Figure 1. (b) Scatter plot showing the data viewed along the stigmatic axis. Only a single set of axes are presented showing light (red) and dark (green) condition data. The orientations of the major axes of the two ellipsoids are noticeably different, indicating the change in antistigmatic variation in response to the stimulus conditions. 
Table 1. Mean refractive state for light and dark conditions and mean dark refraction shift given in complete conventional and component notation.

( * The ortho-antistigmatic mean seems incorrect but round-off has resulted in this apparent discrepancy).

\begin{tabular}{|l|l|l|l|l|l|l|}
\hline & Sph & Cyl & Axis & $F_{\text {st }}$ & $F_{\text {or }}$ & $F_{\text {ob }}$ \\
\hline Light & 0.57 & -0.35 & 29 & 0.40 & 0.09 & 0.15 \\
\hline Dark & 0.02 & -0.39 & 29 & -0.17 & 0.11 & 0.16 \\
\hline $\begin{array}{l}\text { Mean dark } \\
\text { refration shift }\end{array}$ & -0.55 & -0.04 & 20 & -0.57 & $0.01 *$ & 0.01 \\
\hline
\end{tabular}

Table 2. Variances and covariances in $\mathrm{D}^{2}$ of the coefficients of power; $s_{11}$, $s_{22}$, and $s_{33}$ represent the stigmatic $\left(F_{\mathrm{st}}\right)$, the ortho-antistigmatic $\left(F_{\text {or }}\right)$ and the oblique antistigmatic $\left(F_{\mathrm{ob}}\right)$ coefficients respectively. $s_{12}, s_{13}$ and $s_{23}$ represent the stigmatic-ortho-antistigmatic, stigmatic-oblique antistigmatic and orthooblique antistigmatic covariances respectively.

\begin{tabular}{|l|l|l|l|l|l|l|}
\hline Condition & $s_{11}$ & $s_{22}$ & $s_{33}$ & $s_{12}$ & $s_{13}$ & $s_{23}$ \\
\hline Light & 0.0116 & 0.0037 & 0.0016 & -0.0029 & -0.0006 & 0.0010 \\
\hline Dark & 0.0420 & 0.0063 & 0.0147 & -0.0010 & -0.0084 & 0.0036 \\
\hline
\end{tabular}

Table 3. The term-by-term dark-light variance-covariance ratios are shown. $r_{11}, r_{22}$, and $r_{33}$ indicate the ratio of the stigmatic, ortho-antistigmatic and oblique antistigmatic variance components respectively. $r_{12}, r_{13}$ and $r_{23}$ indicate the stigmatic-ortho-antistigmatic, stigmatic-oblique antistigmatic and ortho-oblique anstigmatic covariance ratios respectively.

\begin{tabular}{|l|l|l|l|l|l|l|}
\hline Condition & $r_{11}$ & $r_{22}$ & $r_{33}$ & $r_{12}$ & $r_{13}$ & $r_{23}$ \\
\hline Ratio & 3.6 & 1.7 & 9.2 & 0.33 & 13 & 3.5 \\
\hline
\end{tabular}

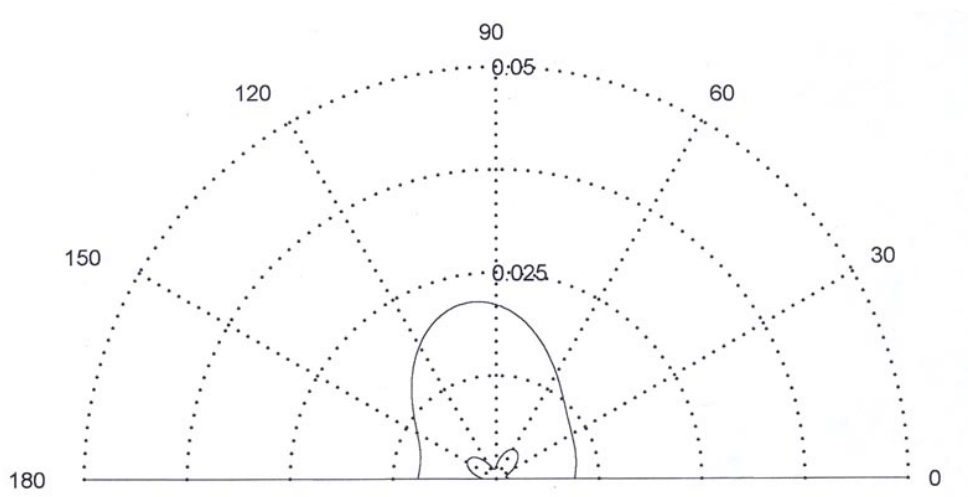

Figure 2 (a). Polar meridional profiles of curvital (larger, outer profile) and torsional (smaller, inner profile) variance are shown. (2a) Light condition. The meridian of maximum curvital variance is close to the vertical meridian.

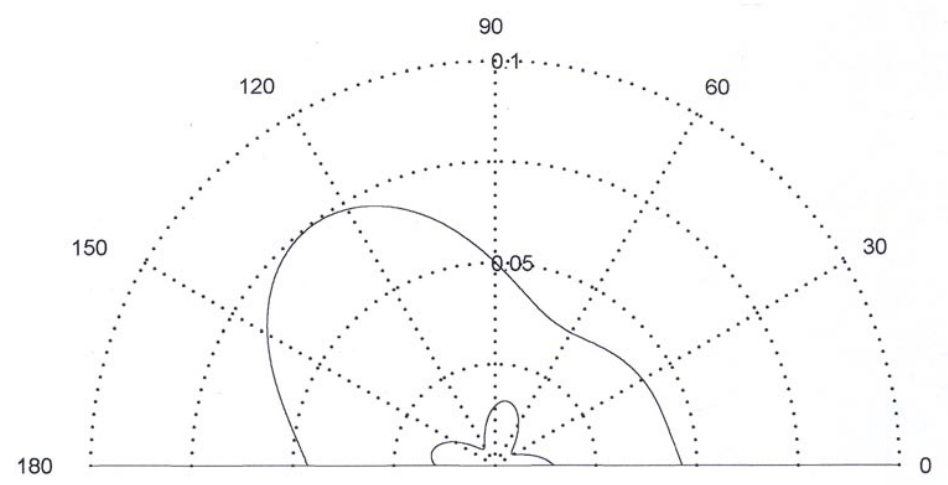

(b) Dark condition. The meridian of maximum curvital variance is approximately 1300. The scale in (b) is twice that in (a). stigmatic coefficients. Also included in Table 1 is the mean dark refraction shift.Figure 1a is a stereo-pair showing 50 measurements of refractive state taken in the light (red) and dark (green). Included for each cluster of measurements are the $95 \%$ ellipsoidal surfaces of constant probability density (distribution ellipsoids). The origin of the axes is $\left[\begin{array}{lll}0 & 0 & 0\end{array}\right] \mathrm{D}$ and the tick intervals are $0.25 \mathrm{I} \mathrm{D}, 0.25 \mathrm{~J}$ $\mathrm{D}$ and $0.25 \mathrm{~K} \mathrm{D}$.

The stereo-pair can be fused by converging the eyes to a point in front of the page, this way the three-dimensional character of the data can be appreciated.

Important aspects of Figure 1a to note are each ellipsoid is elongated parallel, or almost parallel, to the stigmatic axis showing that mainly stigmatic (spherical) variation took place during the measurements. The dark cluster (green) is larger than the light cluster (red) showing the increased variation taking place in the dark, in both the stigmatic and antistigmatic direction (indicated by the larger waist of the green ellipsoid). The dark refraction shift is indicated by the lower positioning of the green cluster (in this orientation) relative to the red cluster.

Table 2 gives the vectorized variance and covariance matrices for the light and dark measurements, units are $\mathrm{D}^{2}$. Table 2 gives the only complete representation of the variance and covariance that exists between the components of refractive state. An important indicator of the difference in variance and covariance that occurred between light and dark measurements is the term-by-term dark-light variance-covariance ratio shown in Table 3.

The important aspects of Table 3 are: the stigmatic variance ratio, 3.6, and the oblique variance ratio, 9.2. The stigmatic ratio shows that there 
was about 3.6 times more stigmatic or spherical, variation occurring in measurements taken in the dark compared with those taken in the light (seen as the greater stigmatic elongation of the green cluster in Figure 1a) while the oblique antistigmatic ratio shows about nine times more variation in the dark indicating the increased antistigmatic variation (seen as the larger waist of the green ellipsoid in Figure 1a). The increased oblique antistigmatic variation is seen in Figure $1 \mathrm{~b}$ and is shown by the larger green ellipsoid that is elongated roughly parallel to the oblique antistigmatic, $\mathbf{K}$, axis. Figure 2 shows polar meridional profiles of variance for the light (Figure 2a) and dark (Figure 2b) data. The outer, larger profiles indicate the curvital variance across meridians and the smaller, inner profile the torsional variance across meridians of the eye. Figure 2a has the largest curvital variance close to the vertical meridian, a phenomenon that has been seen previously and is thought to be due to the blink process. However, Figure $2 \mathrm{~b}$ shows the greatest curvital variance close to the $130^{\circ}$ meridian.

The scale is also larger in Figure 2b, indicating the greater amount of variance occurring under dark conditions, and is also shown in Figure 1a and Tables 2 and 3. It is not clear why the meridian showing the greatest variance should change under light and dark conditions.

\section{Discussion}

Presenting the results of research ${ }^{2-28}$ involving the dark refraction shift in terms of only a spherical component of refractive state is incomplete; such results give no indication of the complexity of the phenomenon. This article has presented the dark refraction shift of a single individual and has emphasized aspects of the phenomenon other than only the spherical component. In particular it shows that the dark refraction shift has an antistigmatic component, that variation occurs in both the stigmatic as well as antistigmatic components and that stigmatic and antistigmatic variation increase under dark conditions.

\section{Acknowledgements}

This note is based, in part, on research sup- ported under grant No 2053699 to WF Harris from the National Research Foundation. We thank Leoni Joubert for helpful comments.

\section{References}

1. Ukai K, Ichihashi Y. Changes in ocular astigmatism over the whole range of accommodation. Optom Vis Sci 199168 812-818.

2. Owens RL, Higgins KE. Long-term stability of the dark focus of accommodation. Am J Optom Physiol Opt 198360 32-38.

3. Ebenholtz SM. Accommodative hysteresis: a precursor for induced myopia. Inv Ophthalmol Vis Sci 198324 513-515.

4. Miller RJ, Wesner MF, Pigion RG, Martin KD. Overaccommodation, underaccommodation and the clinical phoropter: a study of instrument myopia and related effects. Am J Optom Physiol Opt 198461 293-303.

5. Pigion RG, Miller RJ. Fatigue of accommodation: changes in accommodation after visual work. $\mathrm{Am}$ J Optom Physiol Opt 198562 853-863.

6. Ebenholtz Sm. Accommodative hysteresis: relation to resting focus. Am J Optom Physiol Opt 198562 755-762.

7. Accommodativehysteresis: influence on closed loop measures of far point and near point. Inv Ophthalmol Vis Sci 198728 1246-1249.

8. Miller RJ, Takahama M. Effects of relaxation and aversive visual stimulation on dark focus accommodation. Ophthal Physiol Opt 19877 219-223.

9. Fisher SK, Ciuffreda KJ, Levine S. Tonic accommodation, accommodative hysteresis and refractive error. Am J Optom Physiol Opt 198764 799-809.

10. Miller RJ. Effect of pupil size on dark focus accommodation. Ophthal Physiol Opt 1988 8 227-228.

11. Miller RJ, Takahama M. Arousal-related changes in dark focus accommodation and dark vergence. Inv Ophthal Vis Sci 198829 1168-1178.

12. Fisher SK, Ciuffreda KJ, Bird JE. The effect of stimulus duration on tonic accommodation and tonic vergence. Optom Vis Sci 199067 441-449.

13. Ritter AD, Huhn-Beck H. Dark focus of accommodation and nervous system activity. Optom 
Vis Sci 199370 532-534.

14. McBrien NA, Millodot M. Differences in adaptation of tonic accommodation with refractive state. Inv Ophthal Vis Sci 198829 460-469.

15. Rosenfield M, Gilmartin B. Effect of target proximity on open-loop accommodative response. Optom Vis Sci 199067 74-79.

16. Chiu NN, Rosenfield M. Tonic accommodation, tonic vergence and surround propinquity. Ophthal Physiol Opt 199414 290-292.

17. Andre JT, Owens RL, Owens DA. Dark focus values measured by retinoscopy: a clinical chart review. Optom Vis Sci 199875 903-908.

18. PostRB, JohnsonCA, TsuetakiTK. Comparison of laser and infrared techniques for measurement of the resting focus of accommodation: mean differences and long-term variability. Ophthal Physiol Opt 19844 327-332.

19. Post RB, Johnson CA, Owens DA. Does performance of tasks affect the resting focus of accommodation? Am J Optom Physiol Opt 198562 533-537.

20. Bullimore MA, Gilmartin B. Tonic accommodation, cognitive demand and ciliary muscle innervation. Am J Optom Physiol Opt 198764 45-50.

21. Bullimore MA, Gilmartin B. Aspects of tonic accommodation in emmetropia and late-onset myopia. Am J Optom Physiol Opt 198764 499-503.

22. McBrien NA, Millodot M. The relationship between tonic accommodation and refractive error. Inv Ophthalmol Vis Sci 198728 997-1003.

23. Jiang B, Woessner WM. Dark focus and dark vergence: an experimental verification of the configuration of the dual-interactive feedback model. Ophthal Physiol Opt 199616 342-347.

24. Mordi JA, Ciuffreda KJ. Static aspects of accommodation: age and presbyopia. Vis Res 199838 1643-1653.

25. Johnson CA, Post RB, Tsuetaki TK. Short-term variability of the resting focus of accommodation. Ophthal Physiol Opt 19844 319-325.
26. Schor CM, Tsuetaki TK. Fatigue of accommodation and vergence modifies their mutual interactions. Inv Ophthal Vis Sci 198728 1250-1259.

27. Miwa T. Instrument myopia and the resting state of accommodation. Optom Vis Sci $19926955-59$.

28. Miwa T, Tokoro T. Relation between the dark focus of accommodation and refractive error-a cycloplegic study. Optom Vis Sci 199370 328-331.

29. Thibos LN, Wheeler W, Horner D. Power vectors: an application of Fourier analysis to the description and statistical analysis of refractive error. Optom Vis Sci 199774 367-375.

30. Harris WF. Algebra of sphero-cylinders and refractive errors, and their means, variance and standard deviation. Am J Optom Physiol Opt 198865 794-802.

31. Harris WF. Squaring the sphero-cylinder, the equivalent of squaring the refractive power matrix. Ophthal Physiol Opt 19888 458-459.

32. Harris WF. Representation of dioptric power in Euclidean 3-space. Ophthal Physiol Opt 1991 11 130-136.

33. Harris WF. Astigmatism. Ophthal Physiol Opt 200020 11-30.

34. Harris WF. Optical effects of ocular surgery including anterior segment surgery. $J$ Cat Ref Surg 2001 27 95-106.

35. Harris WF, Van Gool RD. Curvital and torsional dioptric power and their polar profiles across meridians. S Afr Optom 199857 3-17.

36. Malan DJ. Dioptric power data analysis: computer implementation of graphical methods with clinical examples. $S$ Afr Optom 199352 84-90.

37. Rubin A. Surfaces of constant visual acuity in symmetric dioptric power space. DPhil thesis, Johannesburg: Rand Afrikaans University, South Africa, 2001. 